\title{
O CoRpo Uma PalaVRa Amordaçada: Da ClíNICA Psicanalítica Ao Âmbito da Saúde Mental
}

\author{
Camila de Freitas Moraes1 \\ Rudimar Mendes2
}

\section{Resumo}

O corpo uma palavra amordaçada: da clínica psicanalítica ao âmbito da saúde mental" tem como objetivo apontar, a partir dos ensinos de Foucault, Freud e Lacan a reflexão sobre o lugar representativo do corpo do louco que tende a ser emudecido seja pela via do excesso de medicalização ou pela exclusão desse sujeito - e que, aparentemente, parece não pertencer a lugar nenhum, nem nos discursos da clínica psiquiátrica, tampouco, nos discursos sociais. Neste trabalho, será exposto o método psicanalítico para se pensar o papel do analista na apreensão do sofrimento psíquico, bem como o desafio na interlocução da psicanálise com o campo da saúde mental. Conclui-se que o corpo do louco, enquanto pertencente ao tecido social, dá ao psicanalista um papel fundante no campo da saúde mental, principalmente, de propiciar que essas palavras não ditas passem a ser ouvidas na cultura. Apostar em uma mudança da relação que o sujeito tem com o seu sintoma, permitindo a ele um espaço da invenção.

PalaVRas-ChaVe: Saúde mental; Normatização do corpo; Corpo na Psicanálise; Poder psiquiátrico.

\footnotetext{
1 Psicóloga, Psicanalista, Especialista em Saúde Mental e Mestranda em Política Social e Direitos Humanos pela Universidade Católica de Pelotas e Taxista PROSUC/CAPES- UCPEL. Rua Gomes Carneiro, 570. Ed. Cavalheiro, 201. Bairro: Porto. Pelotas. Rio Grande do Sul. Cep: 96010-610 E-mail: camilapsi.moraes@yahoo.com.br

2 Psicanalista, Psicólogo, Especialista em Psicanálise, Mestre em Filosofia e Professor dos cursos de graduação e pós-graduação em psicologia do Centro Universitário da Serra Gaúcha - FSG. Rua Moreira César, 2712/52. Bairro: São Pelegrino. Caixas do Sul. Rio Grande do Sul. Cep: 95034-970. E-mail: rudimar-mendes@hotmail.com
} 
O corpo só se torna ser pelas palavras que o recortam e fragmentam seu gozo. O real da pulsão fura a imagem do corpo e é pela palavra que podemos contornar seus furos. (RINALDI, 2011, p.442).

\section{INTRODUÇÃO}

No contexto desse trabalho, o objetivo é circunscrever uma reflexão sobre o corpo como "uma palavra amordaçada", a partir da experiência de um estágio supervisionado de especialização em Saúde Mental em uma Clínica Psiquiátrica, na cidade de Caxias do Sul (RS). Na observação das práxis dos profissionais, que ali atuavam e suas falas acerca da 'loucura', estavam em jogo um 'silenciamento dos corpos', seja pela via do excesso de medicalização - que opera como uma forma de manter esse corpo calmo e normativo - ou pela exclusão desse sujeito que não pertence a lugar nenhum e que não pertence a um lugar social.

Com isso, buscou-se fazer um 'nó' com as questões das relações de poder, de modo a tomar esse corpo como objeto a fim de ser docilizado, domesticado e, por vezes, excluído. A partir dessa perspectiva, repercorre-se os caminhos foucaultianos, freudianos, lacanianos e de seus comentadores para pensar que o "corpo do louco" aparece enquanto sintoma social a partir de diferentes momentos históricos e culturais.

Logo, leva-se a presumir que, supostamente, a loucura pode ser considerada como construção social e pode ser mantida pelas relações de poder pertencentes ao saber psiquiátrico; e, no sentido psicanalítico, buscar-se-á compreender a noção de corpo para tal saber que desde sempre fora marcado por estranheza, uma vez que Freud já apostara na separação daquilo que se apresentava enquanto corpo biológico, e de um corpo outro, chamando-o de corpo psíquico, portanto, marcado pelo desejo.

\section{A Loucura Do Corpo Ao Assujeitamento Do Poder Psquiátrico}

É preciso revisitar o texto foucaultiano, o "Poder Psiquiátrico" ([1973-1974] 2006) para se pensar de que maneira esse 'poder' ainda tem se manifestado como uma 'verdade' sobre o sujeito, uma vez que o lugar dado à doença se curva ante a ação decidida do médico, assim como isso se sustenta nos discursos contemporâneos.

Foucault ([1973-1974] 2006), num primeiro momento, ainda na história antiga, expõe que a loucura e suas manifestações são representadas de forma alegórica e atribuída aos eventos sobrenaturais ligados aos deuses e aos demônios. Já no período inquisitório, a loucura passa a ser uma ameaça à razão, embora ainda esteja 
obstinadamente ligada às representações místicas, tendo em vista que os indivíduos considerados loucos eram identificados como feiticeiros e hereges. Sendo assim, tais manifestações da loucura eram tidas como um castigo dado por Deus diante de alguma prática pecaminosa.

Conforme Vieira (2002) é no período renascentista que a loucura toma uma nova roupagem, ao sair do lugar do divino e a se constituir enquanto expurgo. Ou seja, nessa época era preciso que todo aquele que estava na contramão da racionalidade fosse retirado dos centros urbanos e enviados para grandes embarcações, as chamadas 'nau dos loucos'. Não necessariamente o louco, mas o negro, o homossexual, a prostituta e todo aquele tido como desviante da norma social. Notase, aqui, que o louco era tido como um indivíduo a ser ocultado, a ser invisível.

Já em meados do século XIX, o papel da Medicina atrela-se à regulamentação dos corpos na produção da saúde e da cura aos enfermos, mas, sobretudo, na potencialização da força de trabalho indispensável ao poder estatal, como confirma Birman (1980 apud QUEBRA, 2011, p.33): [...] produção de saúde", articulada "ao poder do Estado, seja como possibilitadora de processos econômicos, já que recupera os corpos dos efeitos dos processos de trabalho, seja como lugar estratégico para o controle das populações". A loucura passa a ser atrelada ao binômio: razão versus irracionalidade, mas agora em uma perspectiva científica, com fins curativos e psicopedagógicos. Isto é, nesse momento, o intuito era o de reestabelecer a sanidade do 'doente mental', de modo terapêutico e assistencialista (VIEIRA, 2002).

Ratificando, Barros (1994) assinala:

\begin{abstract}
O doente mental considerado como homem sem poder social ou econômico, uma presença negativa, "revela-se" como objeto da exclusão, da violência, da agressividade de toda uma sociedade que desejava excluí-lo, mas ao mesmo tempo tornou-se evidente que apenas os "pobres", os deserdados caíam sob essa violência e essa agressividade (BARROS, 1994, p.54).
\end{abstract}

Nesse sentido, o poder sobre o 'corpo louco', é algo a ser disciplinado e a doença mental ainda passa a sofrer pelos estigmas históricos que se reiteram devido as normativas impostas pelo contexto social (FOUCAULT ([1973-1974] 2006).

\title{
O Corpo Atravessado Pela Psicanálise
}

Contrariamente, a Medicina coloca o corpo do louco enquanto objeto do saber médico, tratando-o tão somente enquanto organismo, um corpo experimental, 
O Corpo Uma Palavra Amordaçada: Da Clínica Psicanalítica Ao Âmbito Da Saúde Mental

assujeitado ao outro. Como exemplo, a lobotomia ou a leucotomia a qual fora utilizada como intervenção cirúrgica cerebral com o intuito de tratamento e cura dos pacientes esquizofrênicos em crises agudas (SABBATINI, 1997). A Psicanálise, por sua vez, entende o corpo enquanto signo, o qual traz consigo valores sociais, religiosos, políticos, entre outros aspectos e que se manifestarão de modo particular de acordo com cada cultura. Ou seja, o corpo humano está para além de seu caráter biológico, tendo em vista que o corpo funciona a partir das marcas sociais as quais se atêm (PISETTA, 2016).

Dito isso, ainda é importante expor que o corpo na loucura faz laço com a posição ao qual o sujeito está sobreposto. Berlink (1997) explica: "[...] posição [...] lugar onde uma pessoa ou coisa está colocada" (BERLINK, 1997, p.47), o autor nos faz pensar que o corpo na loucura não é tão somente um lugar de pathos (paixão), de um corpo sexual, mas é também um corpo em que faz referência a um lugar social e, sobretudo, de um corpo passível de se analisar o sofrimento psíquico.

Segundo essa concepção, há algo que se apresenta no corpo do sujeito, que o faz sofrer, daquilo que é pathos, e fora pensando nisso que, ao fim do século XIX e início do XX, Freud (1893-1895/1990) ao se voltar para o estudo dos sintomas histéricos - que até então eram tratados pela medicina vigente como uma patologia sem resposta, tendo em vista que a medicina se propunha apenas a estudar os sintomas a partir da ótica anatômica, desconsiderando assim, quaisquer fatores psíquicos - inaugura a possibilidade do doente, no caso, a histérica, vir a falar sobre o seu sintoma. Como sublinha Lazzarini e Viana (2006) Freud não só rompe com a Medicina Clássica, mas dá vazão a importância de se estudar o corpo para além do caráter biológico, apostando que a partir da fala os afetos que adoeciam o corpo eram extirpados. Freud possibilita o poder da palavra à histérica, assim como o saber sobre o seu próprio sintoma, isto é, eram os pacientes que detinham o saber sobre si e a constituição dos seus sintomas, e não o contrário.

Garcia-Roza (2005) afirma que, nesse sentido, é Lacan que percorrendo os caminhos freudianos demarca a noção de corpo a partir de três eixos: o corpo imaginário demarcado pelo olhar do outro e também sobreposto enquanto objeto de desejo; o corpo simbólico que se constitui a partir do discurso do Outro e o corpo real enquanto inapreensível, embora inclua o corpo orgânico: ossos, tecidos, órgãos. O 
corpo real só pode existir enquanto 'corpo no sentindo psicanalítico', na medida que este for falado, significado.

Logo, pensar o corpo imaginário é levar em conta a metáfora: 'bebê e o Outro materno'. Relação essa composta de unicidade tanto física, quanto psíquica, isto é, uma relação em que a criança anuncia à mãe a possibilidade de satisfazê-la inteiramente em relação a tudo que lhe falta. Neste tempo, o bebê acredita estar diante da completude materna e se identifica enquanto objeto de desejo de sua mãe, sendo o bebê uma sutura imaginária da falta materna. Ou seja, o corpo imaginário é um corpo alienado ao discurso do Outro, que busca uma realidade de si, mas que só encontra a imagem do outro ao qual está alienado. É de suma importância ressaltar que ao se fazer referência a "mãe" não alude à pessoa do sexo feminino, a uma pessoa concreta, mas a um lugar (GARCIA-ROZA, 2005).

Já o corpo simbólico é a articulação que ocorre entre a fala, a linguagem e o corpo biológico, isto é, não basta tão somente que o corpo seja falante, se este não tiver significantes que se relacionem, se encadeiem. Násio (1992/1992) ensina que o corpo simbólico se forma a partir de um emaranhado de palavras que vão se unificando e formando aquilo que a posteriori será chamado de sujeito do desejo, pois como é sabido na teoria psicanalítica lacaniana, o sujeito se constitui através do discurso do Outro anterior a seu nascimento. Logo, a linguagem seria algo que funda a unicidade do ser - o sujeito se identifica pelo nome.

No mais, como bem ilustra Cabas (2010 apud MADEIRO, 2013, p.19): "o sujeito é um ponto e nunca um ser, um ponto entre pulsão e o inconsciente". Sendo assim, o sujeito só se institui como tal a partir da fala, e como bem diz Lacan (1958/1998 apud MADEIRO, 2013, p.19): "o sujeito por si só já sofre por ser sujeito na medida em que esta fala". Dito isso, supõe-se que o sujeito só pode ser constituído no trabalho em análise e vir a emergir a partir dos significantes que o representam. É diante dessa afirmativa que se compreende que o corpo em Psicanálise é banhado pela linguagem (MADEIRO, 2013). Como expõe Násio (1992/1993), o corpo pensando em Psicanálise não é um corpo biológico, mas um corpo marcado pelo significante, ao qual o inconsciente pode vir a ser inscrito e interpretado.

Por fim, o corpo real, que se origina enquanto corpo orgânico, munido de órgãos e tecidos, mas que também se apresenta por meio de processos inconscientes 
a partir da palavra do Outro, ao qual irá significá-lo, poderá simbolizá-lo por meio das marcas no corpo. Com isso, Lacan constitui que é somente por meio do discurso analítico, da fala do sujeito, é que este se torna capaz de significar sua posição diante ao desejo do Outro. Portanto, sobre isso, é crucial explanar o dito por Oliveira (2012):

Se eu disse que o inconsciente é o discurso do Outro, foi para apontar o paraalém em que se ata o reconhecimento do desejo ao desejo de reconhecimento. Em outras palavras, esse outro é o Outro invocado até mesmo por minha mentira como garantia da verdade em que ela subsiste. Nisso se observa que é com o aparecimento da linguagem que emerge a dimensão da verdade. (OLIVEIRA, 2012 apud LACAN, 1957, p. 529).

Logo, o corpo real é inapreensível, não se reduz ao orgânico e só pode existir a partir da fala do Outro, da presença irrevogável do Outro.

\section{O Método Psicanalítico: Uma Aposta Possível}

A Psicanálise, enquanto clínica da escuta e da palavra, tem sido ponto de interlocução com o campo da saúde mental, a partir do trabalho dos analistas nos residenciais terapêuticos, hospitais gerais e Centro de Atenção Psicossocial (CAPS) de modo a dar um outro 'lugar' aos sujeitos que ali se encontram e, por vezes, fazendo emergir 'novas possibilidades' de atendimento no campo da Saúde Mental (LAURENT, 1999).

Então, faz-se crucial expor acerca do método psicanalítico que segundo Couto (2010) parte do singular, daquilo que o sujeito traz como sendo sua verdade, aquilo que este acredita ser, pois como se sabe o sujeito ao qual a psicanálise coloca em voga é aquele regido pelo inconsciente, como bem diz Freud: "o homem não é senhor nem em sua própria morada, nem em seu próprio eu, que é submetido ele próprio, à determinação inconsciente" (p.136). Isto é, o sujeito está para além da consciência e traz consigo semiverdades que se desvelam pelas manifestações inconscientes, manifestações essas que só poderão ser interpretadas pela via da linguagem, pois é por intermédio da fala que o sujeito emerge (COUTO, 2010).

Atualmente se pensar em Psicanálise no contexto de Saúde Mental é estar ciente de que a Psicanálise transcende os muros das clínicas. Está para além do divã, como bem explica o conceito proposto por Laurent (1999) de "analista-cidadão", que se constitui com uma nova cartografia social sobre a inserção do psicanalista no campo da saúde mental e sua importância a qual se torna crucial nesses últimos tempos, uma vez que, ele (psicanalista) busca que o sujeito e/ou paciente se 
responsabilize por seus atos, respondendo por si mesmo, tornando-se assim o sujeito a se implicar e se posicionar frente ao seu tratamento.

Com isso, a Psicanálise como método de tratamento e de investigação se insere em uma ética fundada a partir da solução singular dada pelo sujeito diante do seu desejo. Sendo a estratégia utilizada como método de investigação aquela que se faça presente a associação livre, a escuta flutuante, a transferência e a interpretação como aspectos primordiais para a análise de um sujeito, já que é por meio do enodamento desses que o sujeito se faz perceber (GUERRA, 2010).

\section{CONSIDERAÇÕEs FinaIS}

Em cada momento histórico e sócio-político buscou-se analisar o sofrimento psíquico seja pela via da moralidade, por uma perspectiva psicopedagógica ou científica; para que assim pudesse a vir a compreendê-lo, classificá-lo e tratá-lo. Como Freud (1918) já ensinara: "a Psicanálise é uma análise do psiquismo no sentindo que a química dá a esse termo. Trata-se de decompor, de analisar os elementos que constituem os sintomas e as manifestações patológicas do paciente" (FREUD, 1918 p.202).

Ou seja, nesse recorte temporal, o sofrimento psíquico, que acometia o homem, tinha uma única preocupação: a de classificar a patologia que escapava a 'normalidade'. Mas, é com Freud que ocorre uma ruptura epistemológica, quando este afirma que o sujeito 'louco' sempre fala, especialmente, a partir do seu sintoma, do seu pathos e que isso permite ao analista a possibilidade de interpretá-lo, de lançá-lo no tratamento analítico. Logo, é a partir do seu sintoma que cada sujeito pode vir a dar significado aquilo que the angustia, como assinala Couto (2008, p.137): "A Psicanálise não promete dissipar o mal-estar, não promete nenhum bem e sim um meio diferenciado de posicionamento do sujeito frente ao mal-estar".

Seguindo a mesma lógica, o psicanalista no campo da saúde mental deve operar pelo seu não-saber, é o sujeito suposto saber que está em voga diante do 'corpo louco', pois justamente, aposta-se que o próprio sujeito é detentor do saber sobre aquilo que Ihe causa sofrimento psíquico. Daí a relevância desse trabalho, de demonstrar que há mais que um corpo munido de órgãos e de tecidos, haja vista há um corpo pulsional e nesse está incluso um sujeito e suas singularidades. E aproximar 

Mental

essas questões no campo da saúde mental é apostar em um novo olhar sobre esse corpo que se apresenta enquanto "palavra amordaçada".

Então, pensar o psicanalista e a clínica psicanalítica na instituição de saúde mental significa pensá-la em relação a outros campos de saber (a medicina, a política, o social, entre outras) que ali se encontram e isso está diretamente ligado à forma de se incluir o discurso analítico como ferramenta útil para a compreensão de que o 'corpo do louco' deixe de ser compreendido como um discurso generalista e excludente, para vir a ser pensando em sua singularidade.

No mais, o psicanalista e a clínica psicanalítica têm como papel fundante no campo da saúde mental o de propiciar que essas 'palavras amordaçadas' possam vir a ser ressignificadas e construídas condições e possibilidades para que possam ser ditas e, assim, apostar em uma mudança da relação que o sujeito tem com o seu gozo e/ou sintoma. Dito de outro modo, conclui-se que o analista trabalhe junto a esses 'corpos' no sentindo de construir o advento do sujeito. 


\section{REFERÊNCIAS:}

BERLINCK. Manoel Tosta. O que é Psicopatologia Fundamental. Revista Latino Americana de Psicopatologia Fundamental. [online]. 1997, vol.1, n.1, pp.46-59. ISSN 14154714. Disponível em:< http://www.scielo.br>. Acesso em: 18 abr. 2018.

FOUCAULT. Michel. (2006). O poder psiquiátrico. Curso do Collège de France (1973- 1974). Trad. Eduardo Brandão. São Paulo: Martins Fontes.

FREUD. Sigmund (1918). Linhas de progresso na teoria psicanalítica. Edição standard brasileira das obras psicológicas completas de Sigmund Freud. Vol. XVII, Rio de Janeiro: Imago, 1976.

.(1893-1895) Estudos sobre a histeria. Edição standard brasileira das obras psicológicas completas de Sigmund Freud. Vol. 2. Rio de Janeiro: Imago, 1990.

GARCIA-ROZA. Luiz. Alfredo. Freud e o inconsciente. 21. ed. Rio de Janeiro: Jorge Zahar, 2005.

GUERRA. Andréa Maris Campos. Psicanálise e produção científica. In: NETO, Fuad. Kyrillos.

LACAN. Jacques (1998b). Função e campo da fala e da linguagem na Psicanálise. In: Escritos (p.238-324). Rio de Janeiro: Jorge Zahar (Texto original publicado em 1966).

LAURENT. Éric. A cidade analítica: o analista cidadão. Curinga, Belo Horizonte, MG, n. 13, 1999.

LAZZARINI. Eliana Rigotto; VIANA, Terezinha de Camargo. $O$ corpo em psicanálise. Psicologia: teoria e pesquisa. Brasília, v. 22, n. 2, p. 241-250, 2006

MADEIRO. Roseane. Torres de. O ato infracional entre o gozo e a lei: um enlace possível. 2013. 81 f. Dissertação (Mestrado em Psicologia) - Programa de Pós-Graduação em Psicologia da Universidade Federal do Pará, Belém. 2013.

NÁSIO. Juan David (1992). Cinco lições sobre a teoria de Jacques Lacan. Rio de Janeiro: Jorge Zahar, 1993.

OLIVEIRA, Joyce Bacelar. O inconsciente lacaniano. Psicanálise e Barroco em revista. Belo Horizonte, v. 10, n. 1, p. 109-120, jul. 2012. Disponível em: <http://www.psicanalise ebarroco.pro.br/revista/revistas/19/PeBRev19_9_Oinconscientelacaniano.pdf $>$. Acesso em: 14 abr. 2018.

PISETTA. Maria Angélica Augusto de Mello (2016). Discurso e gozo: Psicanálise e sociedade. Ágora (Rio J.) vol.19 n.1 Rio de Janeiro Jan./Aprovado. 2016. Versão impressa ISSN 15161498E versão on-line ISSN 1809-4414. Disponível em: < http://www.scielo.br>. Acesso em: 10 dez. 2018. 

Mental

RINALDI. Doris. O corpo estranho. Rev. latinoam. psicopatol. fudam. vol.14 no.3 São Paulo Set. 2011. Disponível em:< http://www.scielo.br/scielo.br >. Acesso em: 10 dez. 2018.

SABBATINI. Renato. M. E. A História da Lobotomia. Revista Cérebro \& Mente. Junho de 1997. Disponível em: 〈http://www.cerebromente.org.br>. Acesso em: 26 jul.2017.

VICTORA, Ligia Gomes (2016). Corpo real, corpo simbólico, corpo imaginário. Disponível em: 〈www.appoa.com.br>. Acesso em: 14 abr. 2018.

VIEIRA, Priscila Piazentini. Reflexões sobre a História da Loucura de Michel Foucault. Revista Aulas. Dossiê Foucault, v.1, n.3 - dezembro 2006/março 2007. Org: RAGO, Margareth; MARTINS, Adilton Luís. ISSN 1981-1225. Disponível em: <https: www.ifch.unicamp.br>. Acesso em: 24 jul.2017. 


\title{
The Body Am A DAmaged Word: From PsychoAnAlytic Clinic To Mental Health
}

\begin{abstract}
The body a gagged word: from the psychoanalytical clinic to the mental health field" aims to point, from the teachings of Foucault, Freud and Lacan, the reflection on the representative place of the body of the madman that tends to be muted - whether through the excess of medicalization or the exclusion of this subject - which apparently does not seem to belong anywhere, neither in the discourses of the psychiatric clinic, nor in the social discourses. In this paper, the psychoanalytical method for thinking about the analyst's role in the apprehension of psychic suffering will be exposed, as well as the challenge in the interlocution of psychoanalysis with the mental health field. It is concluded that the body of the madman, as belonging to the social fabric, gives the psychoanalyst a fundamental role in the field of mental health, mainly, to enable these unspoken words to be heard in culture. Bet on a change in the relationship that the subject has with his symptom, allowing him a space of invention.
\end{abstract}

KEYWORDS: Mental Health; Normalization of the body; Body in psychoanalysis; Psychiatric power 

Mental

\section{Le Corps Suis Un Mot Endommagé: De La Clinique Psychanalytique À la Santé Metale}

\section{RÉSUMÉ}

"Le corps 'une parole bâillonnée': de la clinique psychanalytique au domaine de la santé mentale" vise à pointer, à partir des enseignements de Foucault, Freud et Lacan, la réflexion sur la place représentative du corps du fou qui a tendance à être assourdi - que ce soit par l'excès de la médicalisation ou par l'exclusion de ce sujet qui apparemment ne semble appartenir nulle part, ni dans les discours de la clinique psychiatrique, ni dans les discours sociaux. Dans cet article, nous exposerons la méthode psychanalytique utilisée pour réfléchir au rôle de l'analyste dans l'appréhension de la souffrance psychique, ainsi que le défi que pose l'interlocution de la psychanalyse avec le domaine de la santé mentale. II est conclu que le corps du fou, appartenant au tissu social, confère au psychanalyste un rôle fondamental dans le domaine de la santé mentale, principalement pour permettre à ces mots tacites d'être entendus dans la culture. Pariez sur un changement dans la relation que le sujet entretient avec son symptôme, lui permettant ainsi un espace d'invention.

MOTS-CLÉS: Santé mentale; Normalisation du corps; Corps en psychanalyse; Puissance psychiatrique. 
RECEBIDO EM 31-07-2019

APROVADO EM 25-10-2019

(C) 2019 Psicanálise \& Barroco em revista

http://www.seer.unirio.br/index.php/psicanalise-barroco/index

revista@psicanaliseebarroco.pro.br

Programa de Pós-Graduação em Memória Social — UNIRIO

Memória, Subjetividade e Criação

www.memoriasocial.pro.br/proposta-area.php 